\title{
NAMESTYLE SEBAGAI PENCITRAAN VISUAL SEBUAH FILM ANIMASI
}

\author{
Rina Kartika; Tunjung Riyadi \\ Jurusan Desain Komunikasi Visual, School of Design, BINUS University \\ Jln. K.H. Syahdan 9, Palmerah, Jakarta Barat 11480 \\ rinakartika@binus.edu, triyadi@binus.edu
}

\begin{abstract}
Animation movie is one communication media. Image shape that could give reality impression to be interested message sender. History showed that special animation movie gives its own space and style to impress the audience. It is factual that audiences in any ages could acknowledge and enjoy animation moview. The fastmoving development of animation is along with the development of animation technology. Other factor is about promotion and story appeal of related movie. Promotion and story will give identity towards movie title. The movie title, which written suitably, has different appeal that will approach audience to watch the movie. In defining title and identity, there are different ways and designs, so the identity will last remain in the mind of the reader. The article describes namestyle and its relation with characters in some movies, especially Hollywood animation movie.
\end{abstract}

Keywords: namestyle, title design, visual image, animation movie

\begin{abstract}
ABSTRAK
Film animasi merupakan salah satu media komunikasi. Bentuk imaji yang memberi kesan realita menjadi penyampai pesan yang cukup digemari. Sejarah menunjukkan film khusus animasi memberi ruang dan gaya tersendiri dalam memikat penontonnya. Sangat nyata bahwa penonton dalam golongan usia bisa menerima dan menikmati film animasi. Pesatnya perkembangan animasi tidak terlepas dari perkembangan teknologi pembuatan animasi. Faktor lain adalah masalah promosi dan daya tarik cerita film terkait. Promosi dan cerita inilah yang kemudian diberi identitas yang berwujud judul film. Judul film yang ditulis dengan tepat merupakan daya tarik tersendiri yang mendorong seseorang untuk menonton film tersebut. Penentuan judul dan pemberian identitas ternyata punya cara dan desain tersendiri hingga memberi identitas yang melekat di benak calon penonton. Artikel menguraikan desain judul (namestyle) dan kaitannya dengan karakter yang muncul dalam beberapa film, khusus animasi Hollywood.
\end{abstract}

Kata kunci: namestyle, desain judul, citra visual, film animasi 


\section{PENDAHULUAN}

Sejarah menunjukkan film khusus animasi memberi ruang dan gaya tersendiri dalam memikat penontonnya. Sangat nyata bahwa penonton dalam berbagai golongan usia bisa menerima dan menikmati film animasi. Pesatnya perkembangan animasi tidak terlepas dari perkembangan teknologi pembuatan animasi. Pemanfaatan teknologi animasi memungkinkan eksplorasi fantasi tanpa batas bagi dunia perfiman. Hal ini mendorong dimunculkannya kategori khusus bagi film animasi pada ajang penghargaan film tingkat internasional.

Faktor lainnya adalah masalah promosi dan daya tarik cerita film terkait. Promosi dan cerita inilah yang kemudian diberi identitas yang berwujud judul film. Judul film yang ditulis dengan tepat merupakan daya tarik sebuah pencitraan visual yang memberikan persepsi tersendiri bagi calon pemirsa dan mendorong untuk menonton film tersebut. Hal ini tentunya juga mampu menciptakan pencitraan visual positif yang melekat di benak pemirsa setelah menyaksikan film tersebut, sehingga memudahkan untuk diasosiasikan dengan benda promosi (merchandise) sebagai media promosi lanjutan film tersebut.

\section{METODE}

Artikel akan menguraikan penerapan desain judul (namestyle) dalam film animasi. Namestyle adalah tulisan yang terbentuk dari kumpulan huruf, tanpa penambahan gambar tetapi dimungkinkan untuk dimodifikasi dengan tujuan menonjolkan tulisan tersebut. Umumnya namestyle memiliki petunjuk aplikasi penggunaan. Dalam artikel ini akan diuraikan beberapa tipografi judul film animasi box office produksi Hollywood.

Analisis menggunakan penelitian deskriptif sebagai alat untuk menemukan karakter tipografi judul film pada film animasi. Karakter tipografi akan memberikan pencitraan visual yang memungkingkan untuk menyambut calon pemirsa dengan memberikan gambaran awal tentang dunia fantasi film animasi terkait.

\section{PEMBAHASAN}

Tipografi sebagai unsur utama dari judul film animasi menjadi sangat penting peranannya sebagai pencitraan visual dari film animasi terkait. Judul film sebaiknya divisualisasikan dalam bentuk namestyle agar dapat dapat memberikan pencitraan awal kepada calon penonton. Rangkaian huruf dalam sebuah kata maupun kalimat, apalagi sebagai judul, maka fungsi dan bentuknya sudah dikategorikan sebagai logo. Sebagai logo, berarti berfungsi juga sebagai brand. Maka judul dan desain visualnya berarti sebagai logo dan brand name harus memiliki suatu makna dan kemampuan untuk menyuarakan suatu citra ataupun kesan secara visual yang terkait dari film tersebut.

Terdapat dua fungsi pada tipografi, yaitu fungsi estestis dan fungsi komunikasi. Sebagai fungsi estetis, tipografi digunakan untuk menunjang penampilan sebuah pesan agar terlihat menarik, kemudian fungsi komunikasi digunakan untuk menyampaikan pesan atau informasi beberapa teks dengan jelas dan tepat. Sihombing (2001) menyatakan bahwa tipografi adalah ilmu yang secara spesifik mempelajari mengenai huruf. Pengetahuan mengenai huruf yang dipelajari dalam sebuah disiplin seni disebut tipografi. 


\section{Keterkaitan Tema dan Tokoh Utama Film Animasi dengan Desain Judul}

Pada contoh berikut akan menampilkan kajian keterkaitan antara tema film dan tokoh utama sebagai ide dasar desain sebuah judul film. Penulis hanya membatasi film-film animasi yang diproduksi oleh studio besar dari Amerika, yang lebih dikenal mayor studio dari Hollywood. Sebagian besar adalah produksi studio animasi Pixar dan Dreamworks. Film-film tersebut adalah Shrek, A Bug's Life, Gnomeo and Juliette, Tangled, Casper dan Up.
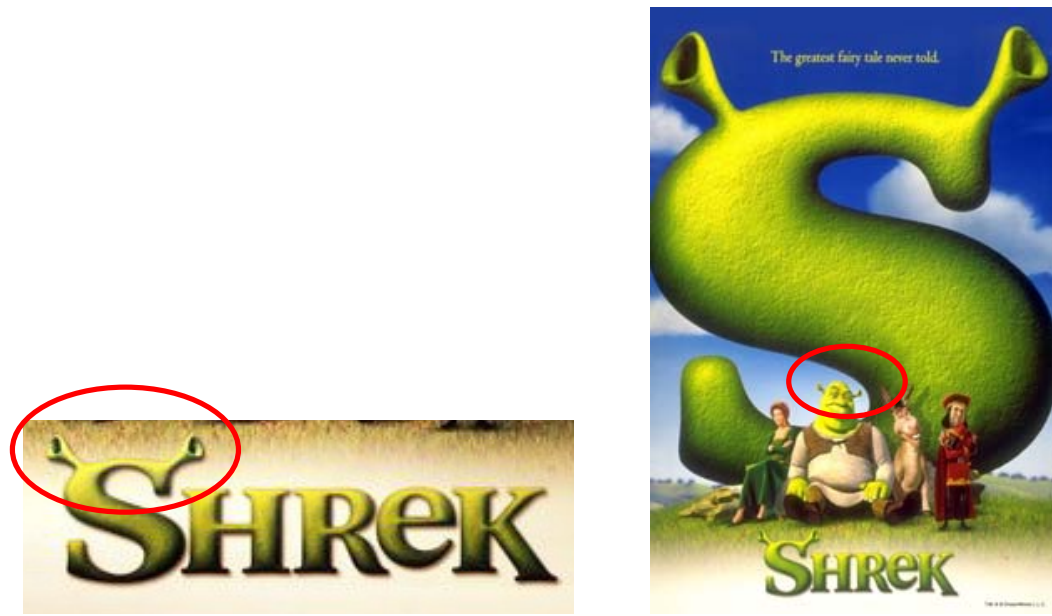

Gambar 1 Desain judul dan poster film Shrek dan poster film Shrek

Film Shrek ditayangkan pada tahun 2001. Film ini menceritakan Ogre, makhluk yang berwajah buruk, berbadan besar dan berkulit hijau. Dalam Gambar 1, ciri khasnya terletak pada bentuk telinganya. Pada desain judul, bentuk telinga menjadi bagian dari desain judulnya. Sintaktik yang dibentuk merujuk pada kesamaan warna, stilasi huruf yang meyerupai telinga dan tekstur tipografi yang berkesan 3 (tiga) dimensional.
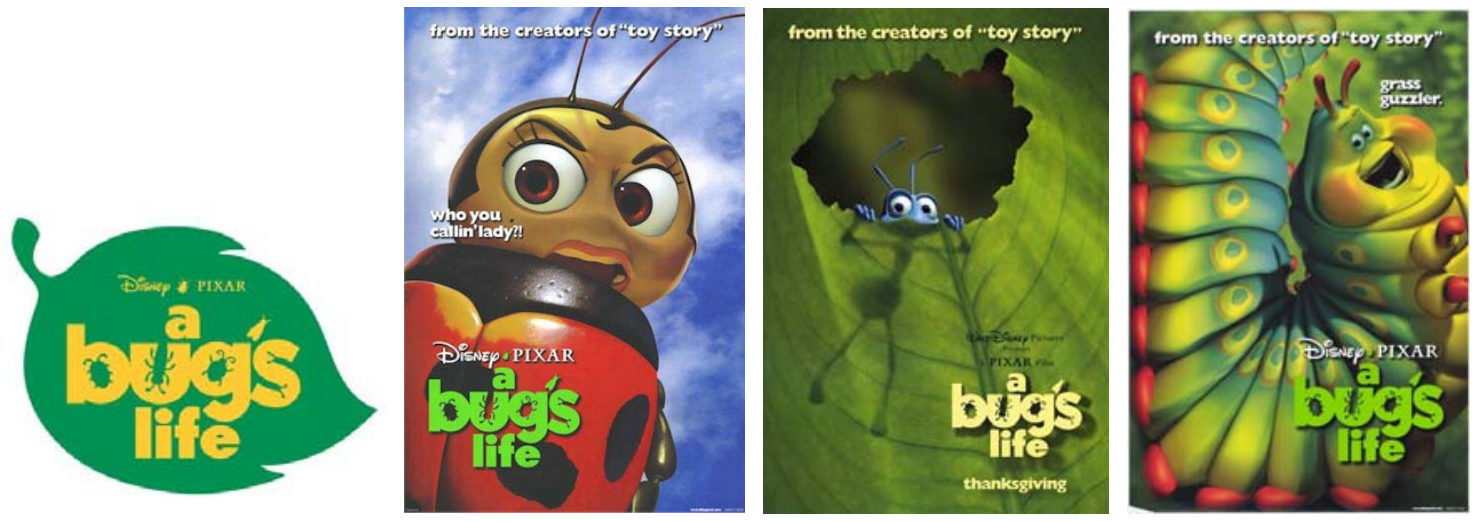

Gambar 2 Desain judul dan poster film A Bug’s Life

Film A Bug's Life ditayangkan pada tahun 1998. Film ini menceritakan kawanan semut yang hidup saling bekerja sama, hingga akhirnya datang sekelompok musuh berupa serangga lain yaitu belalang. Desain judul film ini (dalam Gambar 2) menggunakan tipografi kategori sans serif. Dengan huruf yang tebal, memungkinkan adanya simbol atau pictogram yang menyerupai serangga. Lubang 
(bowl) pada huruf B, U, G dan S membentuk simbol serangga. Bentuk demikian sangat kuat dan memberi dampak tersendiri bagi para pemirsa. Semiotika yang dimunculkan adalah simbol serangga tersebut. Dengan melihat namestyle saja, calon penonton sudah bisa menebak tema film tersebut.

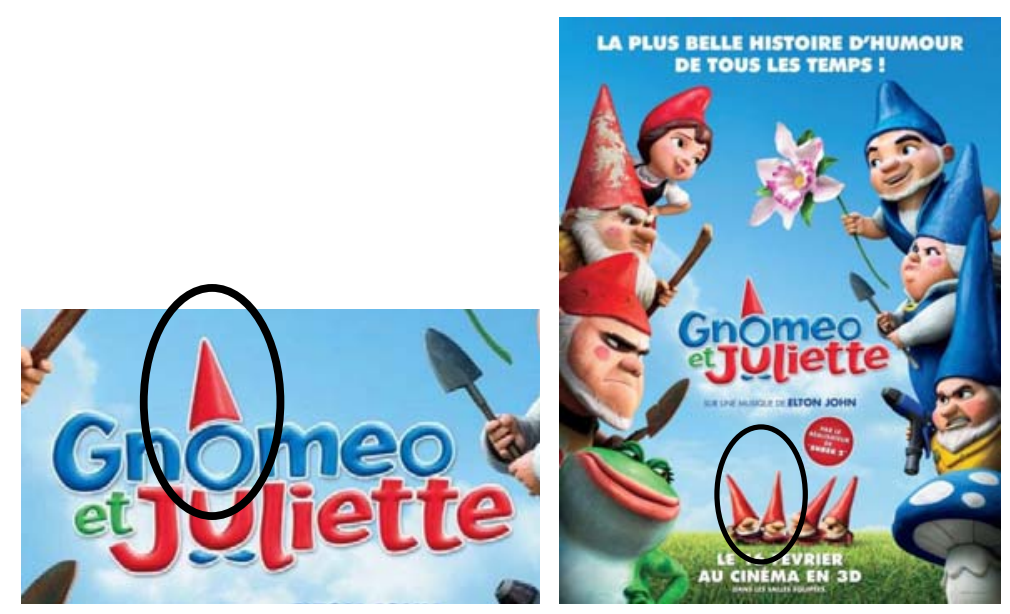

Gambar 3 Desain judul dan poster film Gnomeo and Juliette

Film Gnomeo and Juliette ditayangkan pada 2011. Film ini merupakan versi plesetan kisah tragedi karya William Shakespeare yang berjudul Romeo dan Juliet, dengan tokoh para patung kurcaci yang menghiasi taman. Patung ini mempunyai kehidupan layaknya manusia yang ada di sekitar mereka. Gnomeo dan Juliette berasal dari dua keluarga berbeda yang saling bermusuhan. Cinta mereka tak disetujui dan hubungan mereka punya potensi menyulut peperangan di antara dua keluarga kurcaci ini. Dalam Gambar 3, desain judul film animasi ini menggunakan ilustrasi berupa stilasi seorang kurcaci yang khas pada bentuk topinya, yang terbentuk dari penggabungan huruf 'o' pada kata Gnomeo dan huruf 'u' pada kata Juliette. Penggunaan warna merah dan biru, sesuai dengan warna dua kelompok kurcaci pada cerita film tersebut.

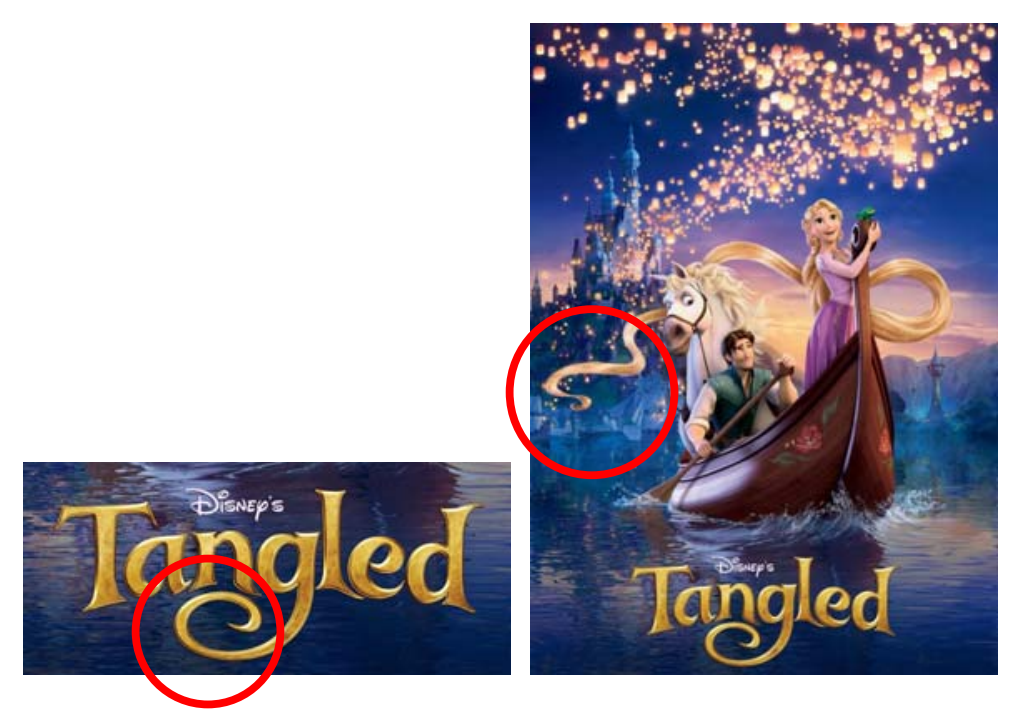

Gambar 4 Desain judul dan poster film Tangled (Rapunzel)

Film Tangled ditayangkan pada 2010. Film ini yang menceritakan mengenai kisah Rapunzel, putri cantik berambut sangat panjang yang seumur hidupnya dikurung dalam sebuah menara yang 
sangat tinggi oleh seorang penyihir. Suatu ketika ia jatuh cinta dengan bandit yang lewat di dekat menara. Sang putri pun memutuskan untuk menemukan sang bandit dan mengambil resiko menjelajah ke dunia luar untuk pertama kalinya agar dapat menemukan pujaan hatinya. Dalam Gambar 4, desain judulnya menggunakan huruf serif, yang dimodifikasi pada descender huruf ' $\mathrm{g}$ ', membentuk panjang rambut. Penggunaan warna emas, yang bertekstur, mendekatkan pada tekstur rambut tokoh film tersebut.
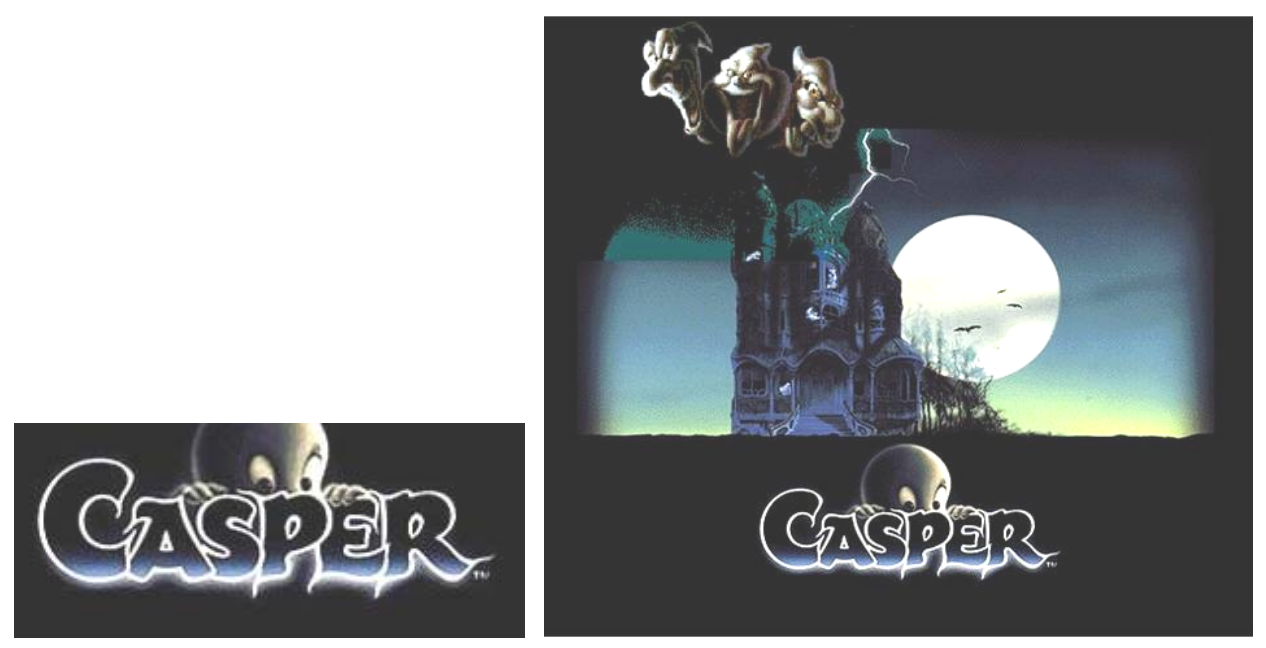

Gambar 5 Desain judul dan poster film Casper

Film Casper, ditayangkan pada tahun 1995, merupakan film animasi bertema drama komedi fantasi yang bercerita mengenai hantu kecil yang baik hati. Dalam Gambar 5, desain judul film ini menggunakan huruf outline dekoratif, yang merupakan stilasi hantu, terbentuk pada garis (stroke) yang meruncing pada setiap ujung akhirnya. Warna yang digunakan adalah putih yang pada bagian bawah berpendar dan transparan.

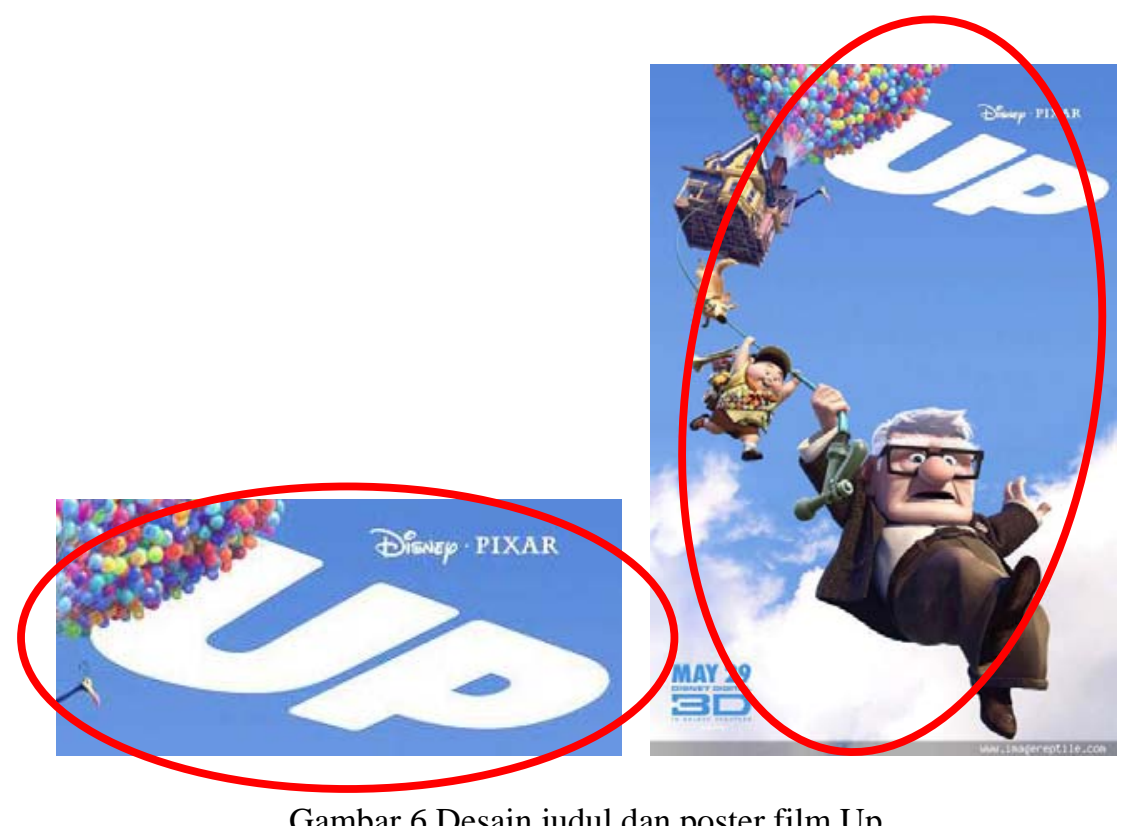


Film Up, yang ditayangkan pada tahun 2009, adalah film animasi tiga dimensi (3D) yang menceritakan petualangan seorang penjual balon ke suatu daerah impiannya. Perjalanan yang dilakukan dengan menggunakan rumah milik penjual balon yang diterbangkan oleh ribuan balon gas. Dalam Gambar 6, desain judul film ini menggunakan huruf sans serif dengan gaya huruf (type style) tebal (bold), dengan sudut pandang perspektif, yang dilihat dari bawah untuk menunjukkan posisi di 'atas' sesuai dengan kisah perjalanan tokoh utama film itu dengan menggunakan balon.
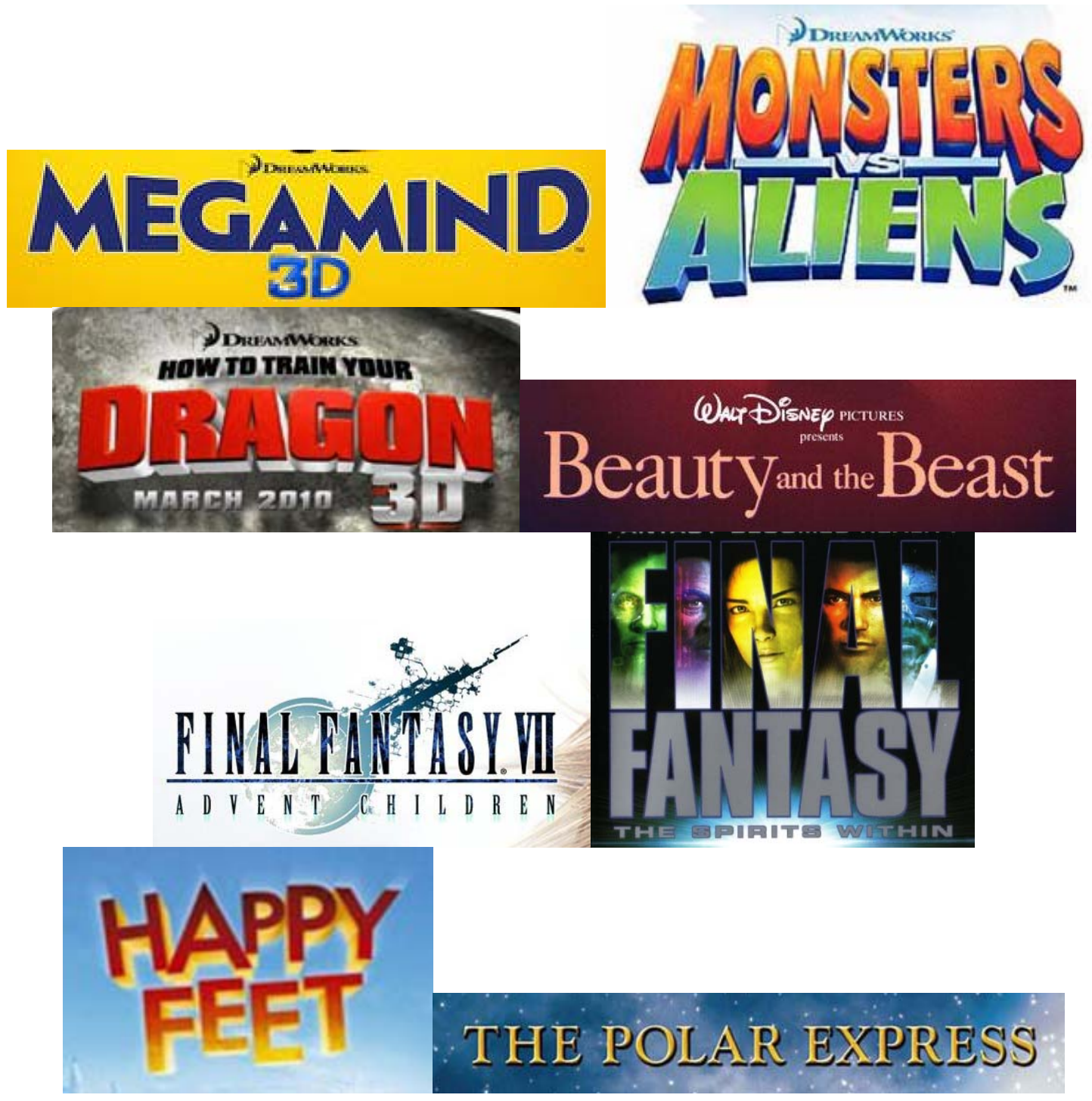

Gambar 7 Namestyle film animasi yang kurang mewakili karakter film

Khusus pada film animasi yang umumnya fiksi yang sarat fantasi, tentunya hal ini akan banyak memberikan nilai tambah, terutama pada segi promosi dan pemasaran. Beberapa film yang namestyle-nya kurang mewakili karakter film adalah Megamind, Monster vs Aliens, How to Train Your Dragon, Beauty and the Beast, Final Fantasy XVII: Advent Children, Final Fantasy: The Spirit Within, Happy Feet, dan The Polar Express. 


\section{PENUTUP}

Tidak dapat dipungkiri bahwa namestyle film menjadi citra visual yang pertama kali diperhatikan penonton. Namestyle yang baik dapat berfungsi sebagai gerbang visual awal yang mengantarkan persepsi menuju dunia fantasi film tersebut bagi para calon penonton.

\section{DAFTAR PUSTAKA}

Bellantoni, J., \& Woolman, M. (2001). Type in Motion: Innovation in digital graphics. London: Thames \& Hudson.

Jury, D. (2002). About face: Reviving the rules of typograpy. Switzerland: Rotovision.

Sihombing, D. (2001). Tipografi dalam Desain Grafis. Jakarta: Gramedia. 